\title{
Copper-Catalyzed Regio-Controlled Oxidative Coupling Polymerization of 2,5-Dimethylphenol
}

\author{
Yuji SHIBASAKI, Yasuo SUZUKI, Mitsuru UEDA ${ }^{\dagger}$ \\ Department of Organic and Polymeric Materials, Graduate School of Science and \\ Engineering, Tokyo Institute of Technology, 2-12-1 O-okayama, Meguro-ku, Tokyo \\ 152-8552, Japan
}

Tel \& Fax: +81 35734 2127, E-mail: mueda@polymer.titech.ac.jp 


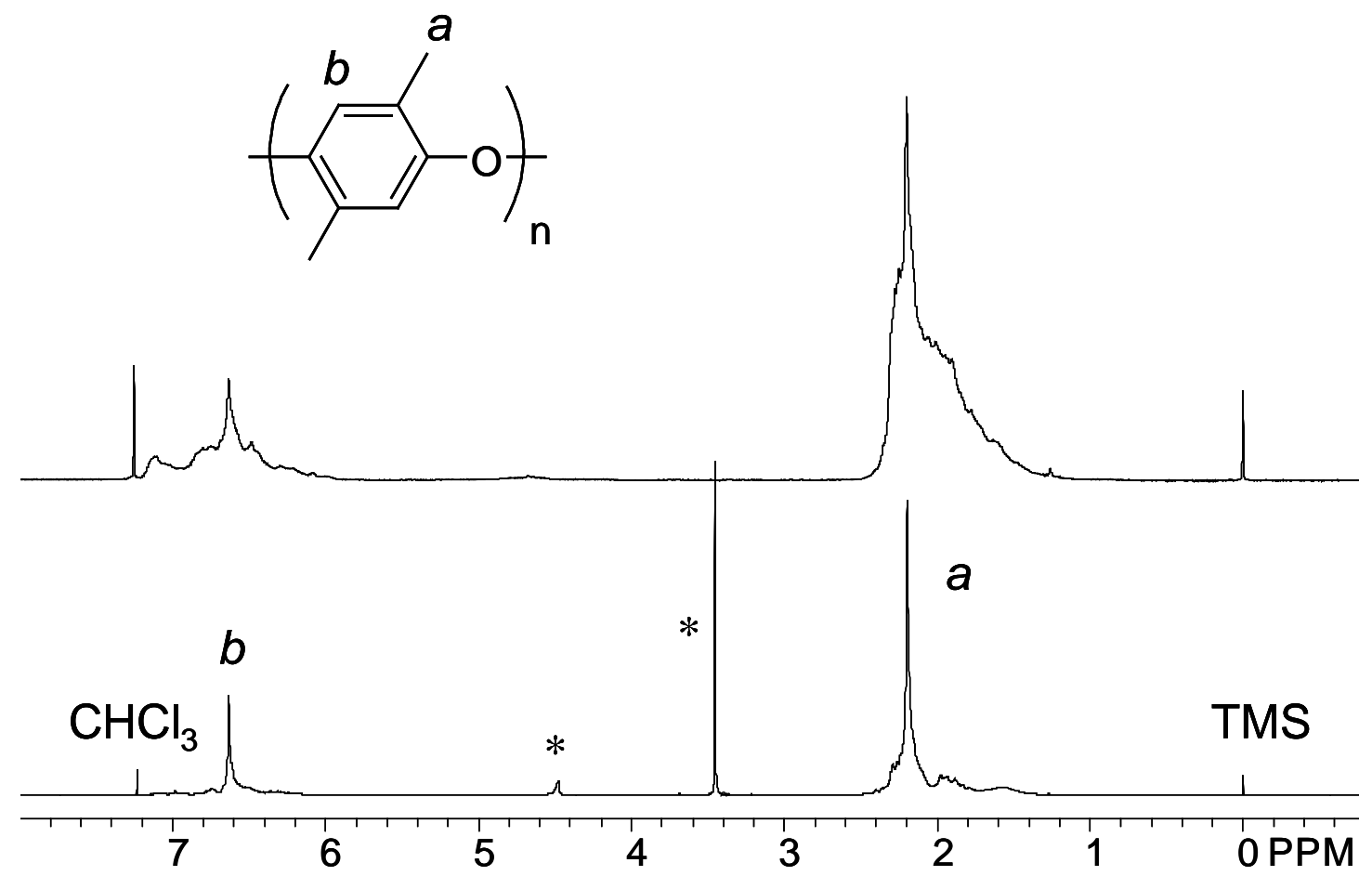

Figure 1S. ${ }^{1} \mathrm{H}$ NMR spectra obtained by $\mathrm{CuCl}-p y r i d i n e\left(40^{\circ} \mathrm{C}\right.$ for $\left.1 \mathrm{~h}\right)$ (top), and the conditions of run 3 in Table 2 (bottom). * $\mathrm{MeOH}$. 


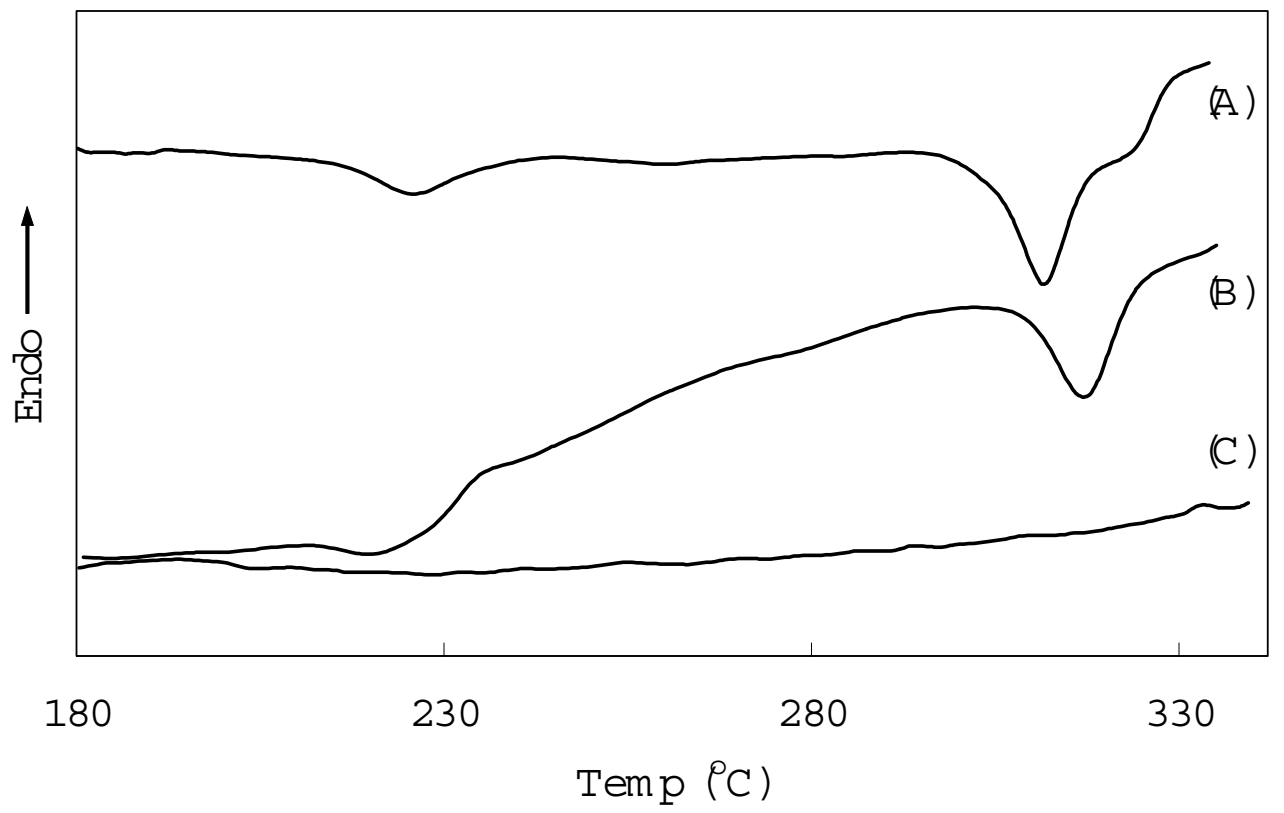

Figure 2S. DSC profiles of the polymers obtained by the conditions in (A) $\mathrm{CuCl} 3 \mathrm{~mol} \%$, 2 -tolylpyridine 100 equiv, $60^{\circ} \mathrm{C} 6 \mathrm{~h}$ (B) run 5 in Table 2 , (C) run 5 in Table 1. 


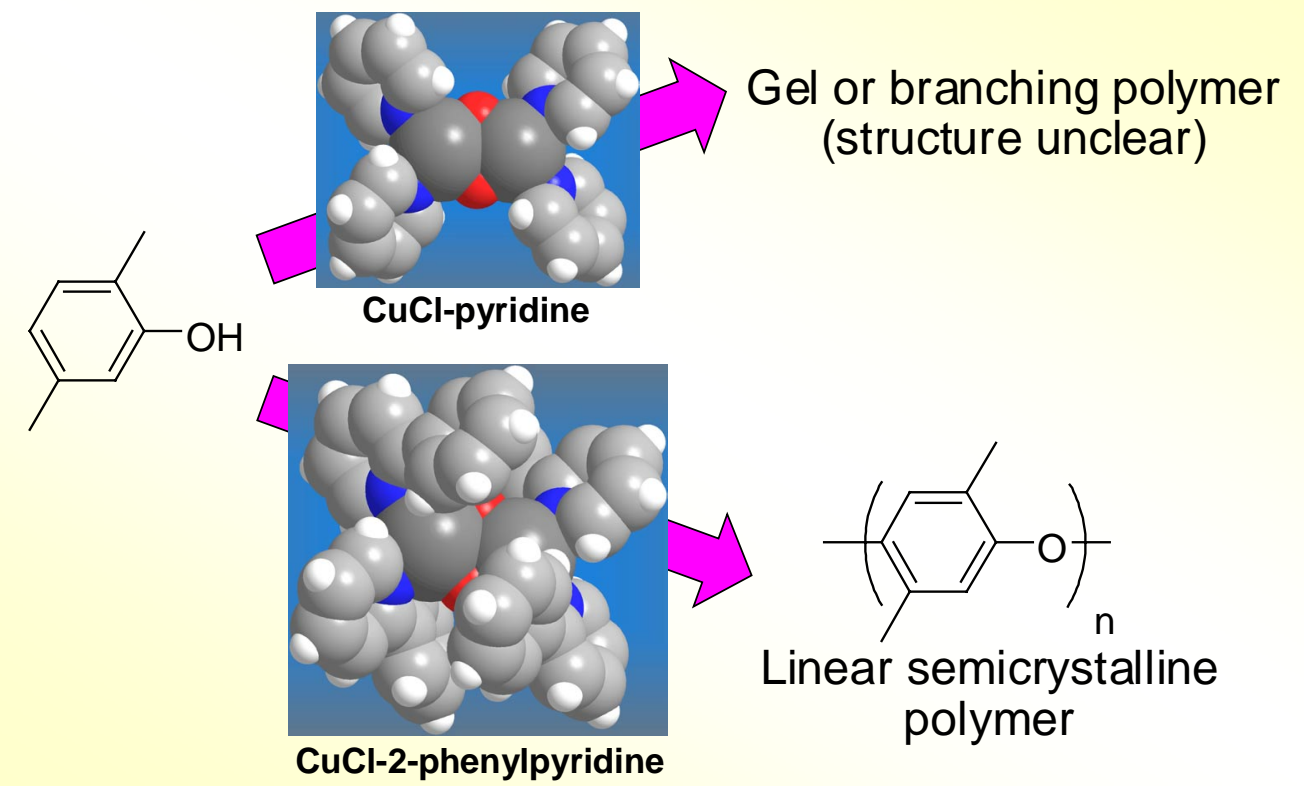

Figure 3S. Polymerization pathways with the different $\mathrm{Cu}$-amine catalysts. The geometry of the copper complex was calculated by DFT method with G96LYP/SDD for Cu and $6-31 \mathrm{G}(\mathrm{d})$ for the other elements. 